\section{The co-incidence of multiple sclerosis in a patient with familial mediterranean fever}

Sir,

Familial mediterranean fever (FMF) is an autosomal recessive inherited inflammatory disorder and in this disease central nervous system (CNS) involvement is uncommon. In 1997, three Turkish patients with FMF and multiple sclerosis (MS) were described, ${ }^{[1]}$ this was followed by other reports from Israel and Turkey. ${ }^{[2-4]}$ In this study, we report the fifth patient of FMF and MS. This patient was not on therapy for FMF, especially colchicine at the time of diagnosis this association.

A 41-years-old female a resident of northwest part of Turkey (Zonguldak) was reffered to our clinic with oneyear history of dizziness, difficulty in walking and hearing loss. She had been diagnosed as a case of MS in an another facility. Further review of her history revealed right eye vision loss with partial resolution without any specific treatment two years before the present visit to the clinic.
In her twenties she was operated for recurrent abdominal pain on three different occasions with the diagnosis of appendicitis, inguinal hernia, and torsion overy. Her father had history of recurrent abdominal pain and died at the age of 43 without any definite diagnosis. She also gave a history of recurrent episodes of skin rash and wrist and knee arthritic symptoms resolving in a week period since several years. Neurological examination revealed afferent pupillary defect, temporal pallor, and diminution in color vision in the right eye, sensorineural hearing loss in the right ear., right hemiparesis (4/5) and right hemihypoesthesia. Tendon reflexes were brisk bilaterally and the plantars were upgoing bilaterally.

Cranial magnetic resonance imaging (MRI) showed multiple hyperintense lesions in the deep and periventricular white matter on T2-weighted images, with generalized atrophy [Figure 1]. MRI of the spinal cord was normal. Evoked potential examinations revealed prolonged P100 latency in the right eye, There were no reproducible somatosensory and brainstem auditory evoked potentials. Laboratory tests showed high sedimentation rate $(80 \mathrm{~mm} / \mathrm{hr})$, high fibrinogen level $(855 \mathrm{mg} / \mathrm{dl})$, and positive CRP $(+++)$. Tests for collagen vascular diseases were negative. Cerebrospinal
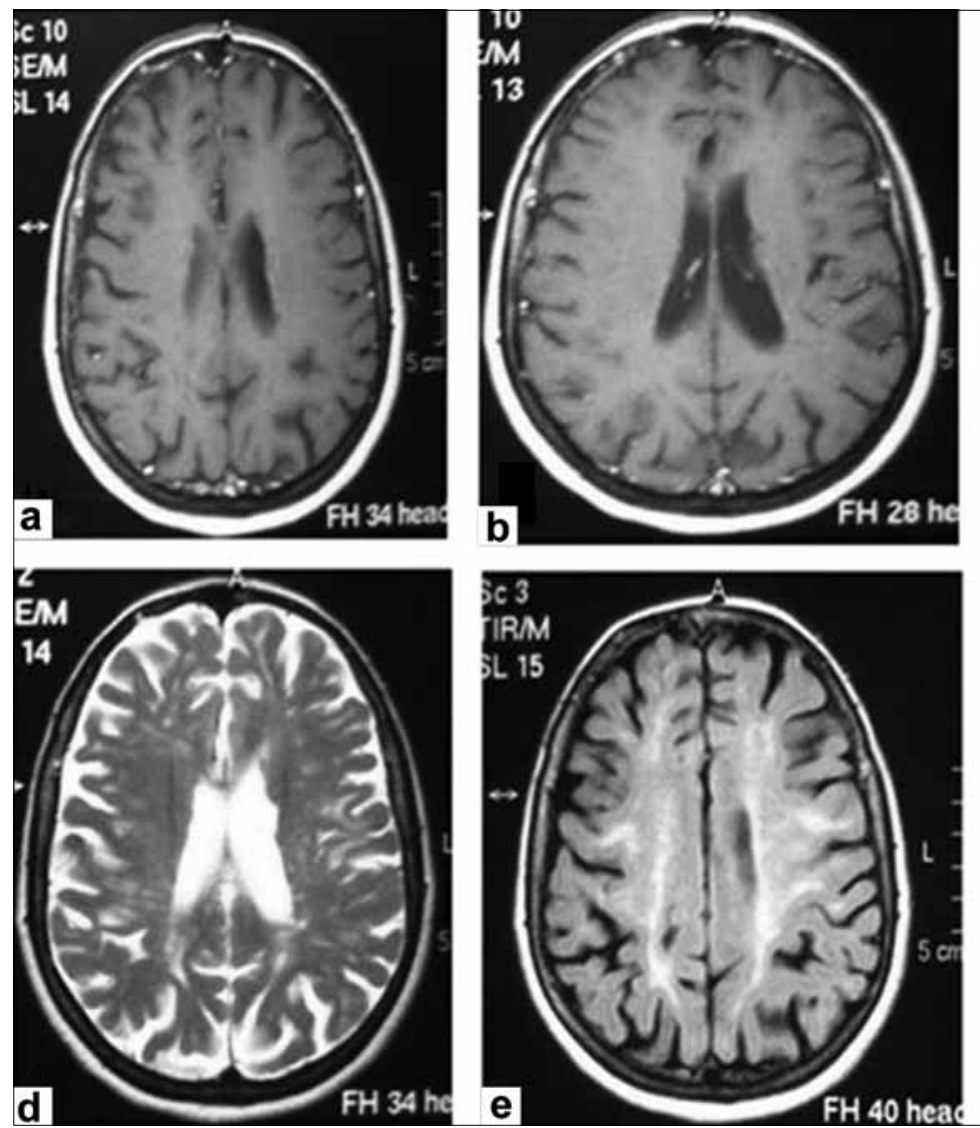
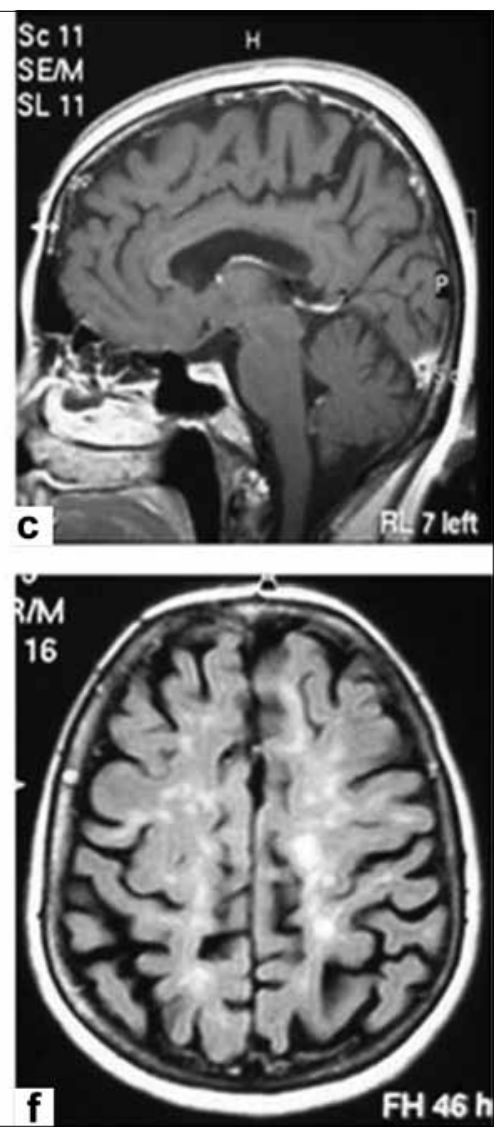

Figure 1: Axial (a-b) and sagittal (c) T1, axial T2 (d) and flair (e-f) brain MRI examination revealed T1 hypointense, T2 hyperintense periventricular lesions without gadolinium enhancement 


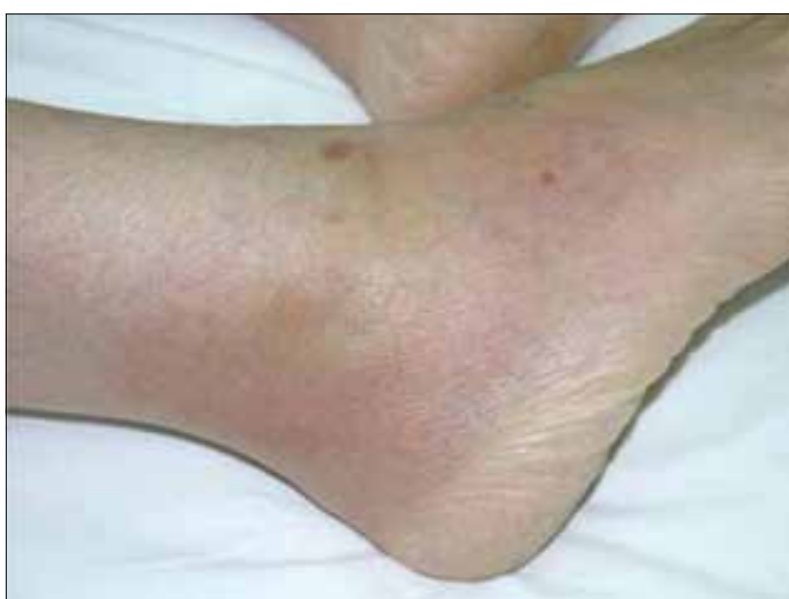

Figure 2: Painful, erythematous skin lesion growing to $15 \mathrm{~cm}$ in diameter, located on the lateral malleolus and dorsum of the foot

fluid (CSF) examination was essentially normal. Schirmer test was $1 \mathrm{~mm}$ in the right and $15 \mathrm{~mm}$ in the left eye. Pathological examination of the minor salivary glands was normal. Ultrasonographic examination of the abdomen revealed splenomegaly $(135 \mathrm{~mm})$ with perihepatic and perisplenic collection.

On the follow-up, the patient developed painful, erythematous skin lesion of $15 \mathrm{~cm}$ in diameter, located on the lateral malleolus and dorsum of the foot [Figure 2]. MEFV gene investigation revealed homozygote mutation for M694V gene. Five pyrin gene mutations (E148Q, M680I, M694V, M694I and V726A) were detected by using the PRONTO ${ }^{\mathrm{TM}}$ FMF Basic Kit according to the manufacturer's instructions. Biopsy specimens from the duedonum and rectum were negative for amyloidosis. A diagnosis of FMF with CNS demyelination was considered and colchicine therapy was started. With colchicine therapy, her symptoms regressed and no further progression of the disease was observed during two years follow-up.

In this patient the diagnosis of FMF was established while she was being worked up for MS. Even the number of reported cases of FMF and MS were limited, mutations of MEFV gene may play an important role in the pathogenesis of multiple sclerosis and studies are needed, especially in mediterranean region, to determine whether MEFV gene is a probable susceptibility gene for MS.

\section{Aysun Ünal, Ufuk Emre, Ahmet Dursun', Selim Aydemir ${ }^{2}$}

Department of Neurology, ${ }^{1}$ Medical Genetics, ${ }^{2}$ Internal Medicine, Zonguldak Karaelmas University, Faculty of Medicine, 67700, Kozlu, Zonguldak, Turkey. E-mail: aysuneu@yahoo.com

PMID: 19934575

DOI: $10.4103 / 0028-3886.57790$

\section{References}

1. Topçuoğlu MA, Karabudak R. Familial Mediterranean fever and multiple sclerosis. J Neurol 1997;244:510-4.

2. Yücesan $\mathrm{C}$, Canyiğit $\mathrm{A}$, Türkçapar $\mathrm{N}$. The coexistence of familial Mediterranean fever with multiple sclerosis. Eur J Neurol 2004;11:715-7.

3. Orbach H, Ben-Chetrit E. Familial mediterranean fever-a review and update Minerva Med 2001:92:421-30.

4. Akman-Demir G, Gul A, Gurol E, Ozdogan H, Bahar S, Oge AE, et al. Inflammatory/demyelinating central nervous system involvement in familial Mediterranean fever (FMF): Coincidence or association? J Neurol 2006;253;928-34.

Accepted on 06-08-2009 